\title{
Increased gastric epithelial cell proliferation in Helicobacter pylori associated follicular gastritis
}

\author{
T J Havard, P Sarsfield, A C Wotherspoon, H W Steer
}

\begin{abstract}
Aims-An increase in the proliferative state of the gastric epithelium has been attributed to infection with Helicobacter pylori. In order to obtain a more precise estimate of the magnitude of this change, the proliferative state of 17 cases of florid $H$ pylori associated follicular gastritis was examined using the antibody MIB-1.

Methods-Comparable results were produced from control and gastritis cases by using a combination of two reproducible measures of the labelled cells. Dividing cells in the gastric mucosa are concentrated within a proliferating compartment, situated at the base of the crypts. This compartment was measured and expressed as a proportion of the total crypt length. The proportion of positively labelled cells within the compartment was also counted.
\end{abstract}

Results-The proliferation compartment in the gastritis cases occupied $45 \cdot 6 \%$ of the gastric crypt compared with $15.4 \%$ in the control group. Of the cells in the proliferating compartment, $79.5 \%$ were positively labelled in the gastritis cases and $33.4 \%$ in the control group.

Conclusions-The convoluted nature of the gastric crypt does not make it a forgiving experimental model. The use of long lengths of mucosa obtained from gastrectomy specimens permitted the production of consistent results, using a morphometric method. The greater than $100 \%$ difference in the proportion of proliferating cells between the two groups suggests that further investigation is warranted.

General Surgery,

E Floor West Wing,

Southampton General

Hospital, Tremona

Road, Southampton

SO9 4XY

T J Havard

$\mathrm{H}$ W Steer

Department of Pathology

P Sarsfield

Department of Histopathology, University College and Middlesex School of Middlesex

University Street,

London WC1E 6JJ

A C Wotherspoon

Correspondence to:

Mr T J Havard,

6 Iestyn Street,

Pontcanna

Cardiff CF1 9HT.

Accepted for publication 20 July 1995 (f Clin Pathol 1996;49:68-71)

Keywords: MIB-1, Helicobacter pylori, gastritis, mucosa

In the past the study of the proliferation of cells in the gastric mucosa has been hampered by the relative morphological complexity of the area. The huge interest created by Helicobacter pylori in the past decade has encouraged a reexamination of the problem, as clear explanations are sought to explain the mechanism of disease in the numerous pathological conditions associated with the bacterium. The association between serological evidence of $H$ pylori infection and adenocarcinoma of the stomach was first reported in $1991^{12}$ and subsequent reports have substantiated the link. ${ }^{3}$

The idea of carcinomatous change occurring in chronically inflamed tissue is well established in the case of ulcerative colitis. A high rate of epithelial proliferation serves as a prognostic indicator in patients with ulcerative colitis at particular risk of developing colon carcinoma. ${ }^{4}$ The question of whether a similar situation exists in the case of chronic gastritis and gastric adenocarcinoma remains unanswered.

Early work on the proliferation kinetics of gastric mucosa described a proliferation compartment, where labelled proliferating cells first appeared. These proliferating cells migrate along the crypt to be eventually shed into the gastric lumen. ${ }^{5}$ The proliferating compartment occupies the region close to the neck of the gastric glands. Once the proliferating cells are labelled histologically, the mucosa is clearly divided into three zones, with the proliferating compartment sandwiched between the superficial crypt and deep glandular zones (figs 1 and 2$){ }^{6}$

While it is clear that the inflammatory response caused by $H$ pylori infection is likely to increase the proliferation rate of the gastric mucosa, moving on from descriptive terms to actually quantifying the change is less straightforward.

At present, there is no universally adopted method for the quantification of labelled, proliferating cells in the gastric mucosa. Most studies have collected biopsy material and obtained a labelling index, by expressing the proportion of positively labelled proliferating epithelial cells in a sample count of predetermined minimum size. ${ }^{6}$

Several variations on this basic methodology have been used. In developing their method of quantifying proliferating gastric epithelial cells in 1975, Hart Hansen et $a l^{7}$ produced a labelling index by counting the proportion of positive cells in each crypt cross-section that contained at least one positively labelled cell. It was realised at the time that the observed values would be an overestimate, because crosssections, within the proliferating compartment, that did not contain a labelled cell were not included in the count. To allow for this, a nomogram was devised, from which a corrected labelling index could be derived from the observed figures. More recently, a novel method has been used to calculate indirectly the mean number of cells in each crypt, and therefore a mean labelling index per crypt. ${ }^{8}$

Our decision to study larger resection specimens was based upon the difficulty we experienced in the orientation of biopsy material. This made morphometric analysis difficult, if not impossible. Larger samples of tissue yield a greater number of crypts for measurement 


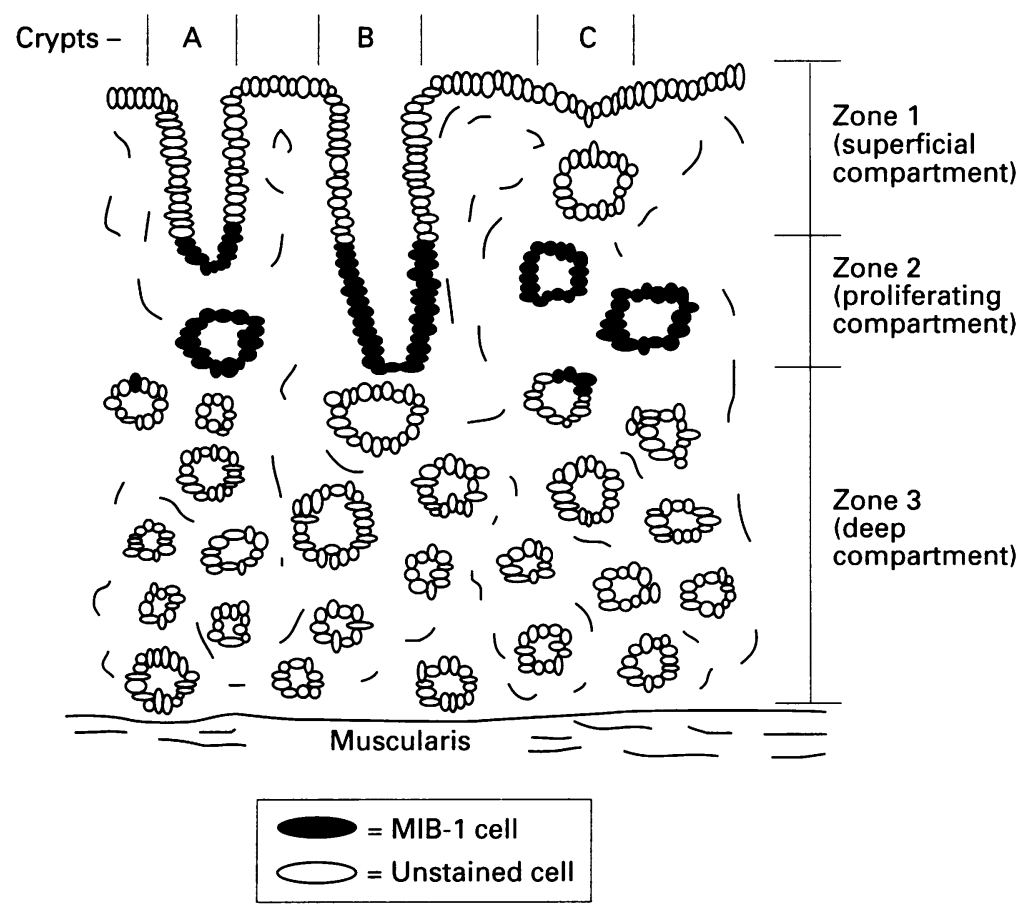

Figure 1 Schematic representation of gastric mucosa stained with MIB-1, showing the three zones. cessing for antigen retrieval, has facilitated the study of proliferating cells in routinely processed, archival tissue. ${ }^{9}$ MIB-1 is reactive to an epitope of the nuclear Ki67 antigen. Although of unknown function, ${ }^{10} \mathrm{Ki} 67$ is known to be present in all stages of the cell cycle apart from $\mathrm{G}_{0}$. In a recent comparison with the thymidine analogue bromodeoxyuridine, MIB-1 proved a reliable indicator of proliferating cells in gastric biopsy material. ${ }^{6}$

\section{Methods}

The tissue used in this study was retrieved from 17 gastrectomy specimens from patients with florid follicular gastritis and MALT lymphoma. In each case the tissue had been fixed in formalin and embedded in paraffin wax. Infection with $H$ pylori was confirmed by positively identifying the bacteria on histological sections stained with modified Giemsa.

To obtain control specimens, we reviewed gastric resection margins from specimens excised because of pancreatic and gastric carcinoma within the past five years. Of the 83 cases reviewed, $77(92.8 \%)$ had some degree of gastritis in the background stomach. Only six cases had no evidence of bacteria, were absolutely clear of inflammatory infiltrate, and were therefore suitable as controls.

The specimens were deparaffinised in xylene and microwaved in an $800 \mathrm{~W}$ oven (Panasonic $\mathrm{NN}-6450$ ), in $0.01 \mathrm{M}$ citrate buffer, at medium power for 25 minutes. ${ }^{9}$ MIB-1 antibody was then applied and the slides incubated at $4^{\circ} \mathrm{C}$ for 24 hours. The specimens were stained using a Streptavidin biotin technique.

Two methods were used to quantify the proliferative state of the epithelium. The length of the proliferative compartment was measured and expressed as a percentage of the total crypt length (fig 3). All measurements were made on a Vesopan microscope, which projects the slide image onto a wax screen, making measurement with a calibrated ruler simple.

In addition, a labelling index was calculated by counting the positively stained cells, and expressing them as a proportion of the total cells in the proliferative compartment (fig 3). Only crypts that were sectioned longitudinally down to the base of the proliferating compartment were included (crypt B in fig 1 ), the rest being used simply as a rough guideline to the deep margin of the zone. The data from these measurements were considered nonparametric and therefore the Mann-Whitney U test was used for statistical analysis. The $95 \%$ confidence limits for the difference between the group medians was also calculated.

\section{Results}

In this series just over $10 \%$ of the crypts were sectioned longitudinally and were therefore suitable for analysis. The mean length of mucosa available in each specimen was $36.5 \mathrm{~mm}$, about 10 times the size of an endoscopic biopsy specimen. In the gastritis and control groups there was a mean of $47 \cdot 7$ crypts available for measurement and cell counting.
Figure 2 Photomicrograph of gastric mucosa stained with $M I B-1$. 


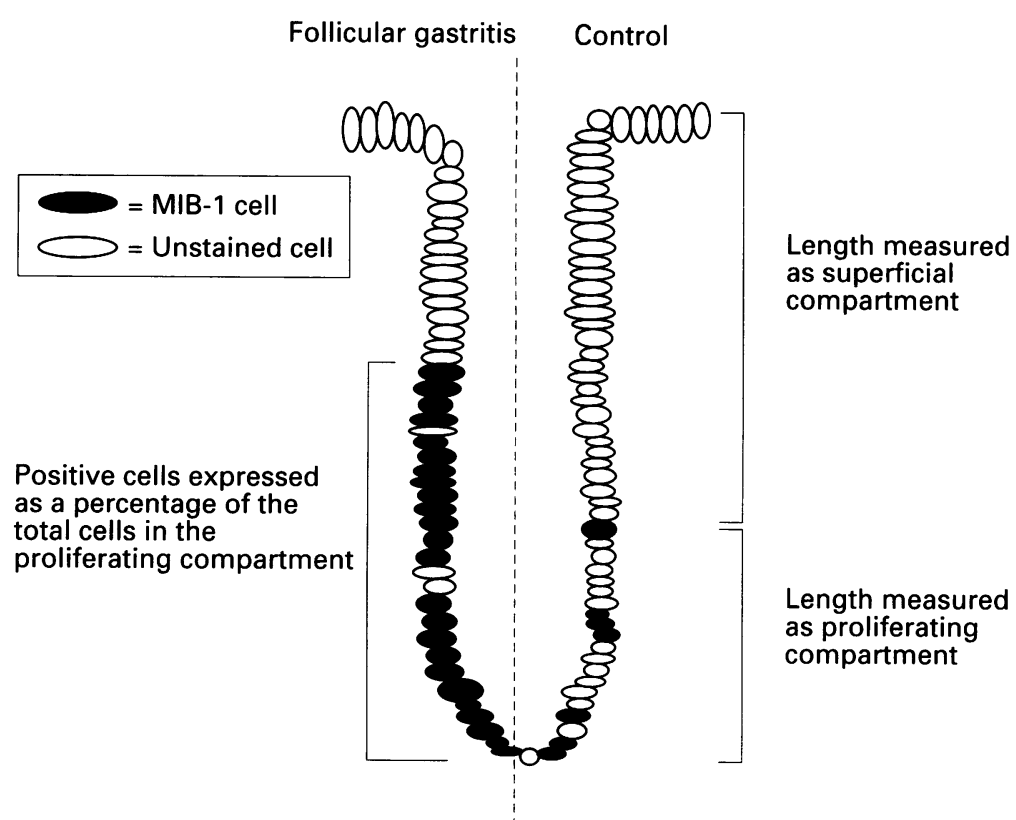

Figure 3 Schematic representation of a gastric crypt stained with MIB-1.

The mean number of crypts per mm length of mucosa in the normal controls was 12 . This figure dropped to 10.9 in the cases with follicular gastritis. This difference in the active, chronic gastritis cases was largely due to thicker lamina propria between the crypts. The crosssectional diameter of the crypts did not vary greatly until the degree of glandular atrophy was noticeable.

Measurements taken in the proliferative compartment revealed that the mean crosssectional diameter, calculated from sample measurements from all of the gastritis cases, was $46.3 \mu \mathrm{m}$ compared with $55.3 \mu \mathrm{m}$ in the control cases. The size of crypts was remarkably constant in the control cases, ranging between 54.2 and $56.6 \mu \mathrm{m}$. In the 17 gastritis cases the range of crypt diameters was far greater, $32 \cdot 5-72 \cdot 3 \mu \mathrm{m}$. The wider crypts occurred in the cases with more advanced mucosal atrophy. The narrower crypts and proportional increase in the thickness of the lamina propria in the gastritis cases may be explained by inflammatory cell infiltrate and oedema.

In each case the positively staining cells were concentrated in the area around the neck of

Summary of results for each case

\begin{tabular}{|c|c|c|c|c|}
\hline \multirow[b]{2}{*}{$\begin{array}{l}\text { Case } \\
\text { no. }\end{array}$} & \multicolumn{2}{|l|}{ Cases } & \multicolumn{2}{|l|}{ Controls } \\
\hline & $\begin{array}{l}\text { Mean \% } \\
\text { proliferation zone }\end{array}$ & $\begin{array}{l}\text { Mean } \% \\
\text { positive MIB-1 cells }\end{array}$ & $\begin{array}{l}\text { Mean \% } \\
\text { proliferation zone }\end{array}$ & $\begin{array}{l}\text { Mean } \% \\
\text { positive MIB-1 cells }\end{array}$ \\
\hline 1 & 45 & $57 \cdot 1$ & $16 \cdot 1$ & $35 \cdot 6$ \\
\hline 2 & $37 \cdot 7$ & $68 \cdot 4$ & $13 \cdot 2$ & 20 \\
\hline 3 & $27 \cdot 8$ & $56 \cdot 1$ & $14 \cdot 6$ & $33 \cdot 8$ \\
\hline 4 & $49 \cdot 2$ & $91 \cdot 1$ & $19 \cdot 3$ & $35 \cdot 7$ \\
\hline 5 & $49 \cdot 1$ & $93 \cdot 6$ & 11.5 & $25 \cdot 1$ \\
\hline 6 & $34 \cdot 3$ & $79 \cdot 5$ & $18 \cdot 7$ & 33 \\
\hline 7 & $37 \cdot 3$ & $65 \cdot 5$ & & \\
\hline 8 & $44 \cdot 5$ & 93.9 & & \\
\hline 9 & 51 & 88.5 & & \\
\hline 10 & $41 \cdot 8$ & $80 \cdot 4$ & & \\
\hline 11 & 43.9 & $75 \cdot 4$ & & \\
\hline 12 & $45 \cdot 6$ & $79 \cdot 4$ & & \\
\hline 13 & $57 \cdot 1$ & $90 \cdot 7$ & & \\
\hline 14 & 47 & $66 \cdot 5$ & & \\
\hline 15 & $50 \cdot 5$ & $80 \cdot 6$ & & \\
\hline 16 & $46 \cdot 4$ & $62 \cdot 1$ & & \\
\hline 17 & $48 \cdot 7$ & $86 \cdot 3$ & & \\
\hline
\end{tabular}

the crypt as expected. The positively stained cells outside this area were sparse and found in the deep, glandular region of the mucosa. The only variation from this pattern was found in regions of intestinal metaplasia in the gastritis cases. Here, although the proliferating cells remained in the region around the crypt neck, this extended deeper into the mucosa, close to the muscularis.

The proliferation results for each case are summarised in the table. Statistical analysis of the non-parametric data was by the MannWhitney $U$ test. The median percentage of the gastric crypt occupied by the proliferating compartment was $45.6 \%$ in the gastritis cases compared with $15.4 \%$ in the control group $(p<0.001,95 \%$ confidence interval of the separation of the medians $24 \cdot 1-34 \cdot 5 \%$ ).

The difference between the two groups is more noticeable when the proportion of positively staining cells is considered. Of the cells in the proliferating compartment, $79.5 \%$ were positively labelled in the gastritis cases and $33.4 \%$ in the control group $(p<0.001,95 \%$ confidence interval of the separation of the medians $32 \cdot 8-58 \cdot 1 \%$ ).

\section{Discussion}

Previous studies have demonstrated that the proliferative state of the gastric mucosa increases in response to infection with $H$ pylori. ${ }^{6}$ Using a straightforward, reproducible technique, we have demonstrated that there is a greater than $100 \%$ increase in the proportion of proliferating cells.

The precise role $H$ pylori plays in the development of gastric carcinoma is unknown. The initial studies reporting on the association between infection and carcinoma were based on the finding that serological evidence of infection was more prevalent in patients with carcinoma than in normal controls. ${ }^{1-3}$ However, there are regions where epidemiological study has shown infection to be highly prevalent from childhood, and yet the population remains at a low risk of developing carcinoma. Gastric carcinogenesis is therefore multifactorial, with $H$ pylori being one of the contributory factors. ${ }^{11}$

It is possible that the bacterium acts indirectly, as an initiator, causing genomic damage by the induction of reactive oxygen molecules by neutrophils and macrophages. It is also possible that $H$ pylori acts as a promoter; the increase in the rate of cell replication, resulting from infection, increasing the cells' vulnerability to other unrelated carcinogens. ${ }^{12}$

The ease with which gastric mucosal tissue can be retrieved by flexible gastroscopy and biopsy makes it an attractive source of material for a study such as this. A problem arises, however, in the convoluted nature of the gastric crypts. This renders the majority of crypts unsuitable for morphometric analysis because of tangential and transverse sectioning.

The difficulty in using gastric biopsy specimens in the study of gastric epithelial cell proliferation was first realised by Hart Hansen $e t$ $a l$ in $1975 .{ }^{7}$ Difficulty in orientation and few longitudinally cut crypts led them to devise 
the rather involved method of mathematically correcting a labelling index obtained from transversely cut material.

In using florid follicular gastritis for this study, we have purposely chosen from the more severe end of the spectrum of $H$ pylori associated gastritis. H pylori gastritis is frequently a patchy disease ${ }^{13}$ and it is therefore probable that our figures, derived from uniformly severe gastritis, are an overestimation of the situation in $H$ pylori infection as a whole.

The distribution of the MIB-1 positive cells in the areas of intestinal metaplasia was similar to that found in studies of proliferation in the colon. ${ }^{4}$ Again, the cells were concentrated in a proliferation compartment at the base of the crypts. As the deep margin of this compartment is much closer to the muscularis, this difference is probably attributable to the associated glandular atrophy. The relative size of the proliferation compartment in the areas of intestinal metaplasia seems to be similar to those in the inflamed crypts, although the number of such crypts was too small to allow analysis of any significance.

In conclusion, our results show that following infection with $H$ pylori there is a greater than $100 \%$ increase in the proportion of gastric epithelial cells undergoing active proliferation. The magnitude of the increase in the number of proliferating cells would seem to be sufficient to warrant further investigation as a potential risk factor for gastric carcinoma.
1 Parsonnet J, Friedman GD, Vandersteen DP, Chang Y, Vogelman JH, Orentreich N, et al. Helicobacter pylori and the risk of gastric carcinoma. N Engl F Med 1991;325: 1127-31.

2 Nomura A, Stemmerman GN, Chyou PH, Kato I, PerezPerez GI, Blaser MJ. Helicobacter pylori infection and gastric carcinoma among Japanese Americans in Hawaii. $N$ Engl f Med 1991;325:1132-6.

3 EUROGAST Study group. An international association between Helicobacter pylori infection and gastric cancer. Lancet 1993;341:1359-62.

4 Biasco G, Paganelli GM, Miglioli M, Brillanti S, Di Febo G, Gizzi G, et al. Rectal cell proliferation and colon cancer G, Gizzi G, et al. Rectal cell proliferation and colon cance
risk in ulcerative colitis. Cancer Res 1990;50:1156-9.

5 Lipkin M, Sherlock P, Bell B. Cell proliferation kinetics in the gastrointestinal tract of man. Gastroenterology 1963; 45:721-9.

6 Lynch DAF, Clarke AMT, Jackson P, Axon ATR, Dixon MF, Quirke P. Comparison of labelling by bromodeoxyuridine, $\mathrm{MiB}-1$, and proliferating cell nuclear antigen in gastric mucosal biopsy specimens. F Clin Pathol 1994;47:122-5.

7 Hart Hansen O, Pedersen T, Larsen JK. A method to study cell proliferation kinetics in human gastric mucosa. Gut 1975;16:23-7.

8 Patel S, Rew DA, Taylor I, Potten CS, Owen C, Roberts SA. Study of the proliferation in human gastric mucosa after in vivo bromodeoxyuridine labelling. Gut 1993;34: 893-6.

9 Cattoretti G, Becker MHG, Key G, Duchrow M, Schluter C, Galle J, Gerdes J. Monoclonal antibodies against recombinant parts of the Ki67 antigen MIB 1 and MIB 3 detect proliferating cells in microwave-processed formalinfixed paraffin sections. $\mathcal{F}$ Pathol 1992;168:357-63.

10 Sawhney N, Hall PA. Ki67 - Structure, function, and new antibodies. $\mathcal{F}$ Pathol 1992;168: 161-2.

11 Correa P. Human gastric carcinogenesis: A multistep and multifactorial process - First american cancer society award lecture on cancer epidemiology and prevention. Cancer Res 1992;52:6735-40.

12 Correa P, Ruiz B. Helicobacter pylori and gastric cancer. In: Rathbone BJ, Heatley RV, eds. Helicobacter pylori and gastroduodenal disease. 2nd edn. Oxford: Blackwell Scientific, 1992:158-64.

13 Dixon MF. Helicobacter pylori and chronic gastritis. In: Rathbone BJ, Heatley RV, eds. Helicobacler pylori and Rathbone BJ, Heatley RV, eds. Helicobacler pylori and
gastroduodenal disease. 2nd edn. Oxford: Blackwell Scientific, 1992:124-39. 